\title{
A Comprehensive Evaluation of a College Course
}

\section{Richard R. Sudweeks and Robert M. Diamond}

No two evaluation designs will be the same. In each instance the evaluation must be structured to serve the information needs of those involved in the decision-making process. There, is, however, a general list of questions that tend to recur in the evaluation of courses and other programs of instruction. The following list has been designed to assist faculty and administrators who are or will be charged with the task of evaluating a course. While no list could ever be considered complete, these items have been developed from efforts on several campuses that have dealt with the design and implementation of new courses and programs as well as the evaluation of existing courses and curricula. The list is intended to be a functional guide in the design stage of an evaluation. It should serve as a checklist making sure that all relevant questions have been considered.

In using this list, it must be remembered that all the questions may not be appropriate in a single project because of limitations in time, staff, and money. It is up to those involved to select the specific questions that should be addressed and to place priorities among them. It is our hope that this list will lead to more responsible decisions regarding which issues will be addressed in the evaluation. Questions which are not included in the evaluation should be omitted intentionally rather than by accident. The evaluation methodology that is elected should match the questions that are being asked.

Following the list you will find an example of the questions selected for use in evaluating two on-going experimental courses (see page 110). 


\section{Consider Each of the Following Questions and Check Those That are Appropriate for the Specific Course Your are Evaluating}

\section{Course Rationale}

A. What population of students is the course intended to serve?

B. What student needs is the course intended to service?

C. What institutional, community or societal needs is the course intended to serve?

D. What other defensible reasons exist for offering this course?

E. What other courses serve these same needs?

F. To what extent does this course overlap with or duplicate these other courses?

_ G. On what grounds is the continued existence of this course justified and warranted?

\section{Development and Current Status of the Course}

A. When and under what circumstances was the course developed?

- B. How frequently and how regularly has the course been offered?

- C. To what extent has the enrollment increased, decreased, or stabilized from year to year?

D. What problems have been associated with the course and how have they been resolved?

- E. To what extent is the course intended to be replicable from instructor to instructor or from term to term?

- F. To what degree do the plans or design for the course exist in a written or documented form? In what documents (course approval forms, course outlines or syllabi, memos, etc.) do these plans exist?

_ G. How does the current version of the course differ from earlier versions? Why? 


\section{Credit and Curricular Implications}

A. What credit is awarded for successful completion of the course? On what basis is this credit allocation justifiable?

B. In what ways can credit for this course be applied towards fulfillment of graduation and degree requirements?

C. At what level (lower division, upper division or graduate) is the course classified? Why? On what basis is this classification justified?

- D. How does the course fit into the overall curriculum of the sponsoring department and college?

_E. In which departments is the course cross-listed? Why? How does it fit into the curriculum of these departments or colleges?

_F. What prerequisite skills or experiences are needed in order to succeed in this course?

G. What problems are experienced by students who do not have these prerequisites?

\section{Course Objectives}

A. What are the formal, stated objectives of the course?

B. How feasible and realistic are these objectives in terms of the abilities of the target population and the available time and resources?

- C. How are the stated objectives related to the adult life- role competencies students will need in everyday life outside of school?

- D. How are the objectives related to the competencies students will need in their subsequent academic careers?

- E. If the course is designed to prepare students for a specific professional or vocational field, how are the objectives related to the competencies they are likely to need in their future careers?

- F. What values are affirmed by the choice of these two objectives as goals for this course?

- G. What other purposes, intents, or goals do the faculty, administrators, and other interested audiences have for the course? 
- H. What goals and expectations do students have for the course?

- I. To what extent are these additional goals and expectations compatible with the stated course objectives?

\section{The Content of the Course}

- A. What (1) information, (2) processes, and (3) attitudes and values constitute the subject-matter or content of the course?

- B. How are the various content elements related to the course objectives?

- 1. Which objectives receive the most coverage or emphasis? Why?

2. Which objectives receive only minor coverage? Why?

_ C. How is the content sequenced or arranged? Why is this sequence appropriate/inappropriate?

- D. What means are used to integrate and unify the various content elements into a coherent pattern or structure? To what extent does fragmentation or lack of coherence appear to be a problem?

_E. What values and assumptions are implicit in the decisions which have been made regarding content selection and emphasis?

\section{Instructional Strategies}

A. What kinds of learning activities are utilized?

- 1. What activities are the students expected to engage in during class sessions?

2. What assignments or projects are students expected to complete outside of class?

_ 3. In what ways are these activities appropriate or inappropriate in light of the course objectives?

4. How could these activities be made more effective?

_B. What instructional materials are utilized?

- 1. How and for what purpose are the materials used?

- 2. How accurate and up-to-date are the materials?

-3. In what ways do the materials need to be improved?

- 4. How could the materials be utilized more effectively? 
- C. What instructional roles or functions are performed by the teacher(s)?

- 1 . How could these roles be performed more effectively?

- 2. What important instructional roles are not provided or are performed inadequately? Why?

-D. What premises and assumptions about learning and the nature of the learner underly the selection of instructional strategies? How and to what extent are these assumptions warranted?

\section{Procedures and Criteria for Evaluating Students'}

\section{Achievement}

A. What instruments and procedures are employed as a means of collecting evidence of the students' progress and achievement?

B. What criteria are used to assess the adequacy of the students' work and/or achievement? On what basis were these criteria selected?

- C. How well do the assessment procedures correspond with the course content and objectives? Which objectives or content areas are not assessed? Why?

- D. To what extent do the assessment procedures appear to be fair and objective?

_ E. What evidence is there that the assessment instruments and procedures yield valid and reliable results?

_ F. How are the assessment results used? Are the results shared with the students within a reasonable amount of time?

_ G. How consistently are the assessment criteria applied from instructor to instructor and from term to term?

- H. What indications are there that the amount of assessment is excessive, about right or insufficient?

\section{Organization of the Course}

- A. How is the course organized in terms of lectures, labs, studios, discussion sections, field trips and other types of scheduled class sessions? 
B. How frequently and for how long are the various types of class meetings scheduled? Is the total allocation of time sufficient/insufficient? Why?

- C. If there is more than one instructor, what are the duties and responsibilities of each? What problems result from this division of responsibilities?

_D. What outside-of-class instruction, tutoring or counseling is provided? By whom? On what basis?

_ E. How well is the student workload distributed throughout the course?

_ F. To what extent are the necessary facilities, equipment, and materials readily available and in good working condition when needed?

\section{Course Outcomes}

A. What proportion of the enrollees completed the course with credit during the regular term? How does the completion rate vary from instructor to instructor or from term to term?

_ B. What proportion of the enrollees withdrew from or discontinued attending the course? Why?

- 1. To what degree does their discontinuance appear to be related to factors associated with the course?

- 2. How does the attrition rate vary from instructor to instructor or from term to term?

- C. At the end of the course, what evidence is there that students have achieved the stated objectives?

- 1. For which objectives was the course most/least successful?

2. For what kinds of students was the course most/least successful?

-D. What effects does the course appear to have had upon students' interest in the subject-matter and their desire to continue studying and learning about this subject?

- E. What other effects did the course have upon the students?

- 1 . How were their values, attitudes, priorities, interests or aspirations changed? 
2.How were their study habits or other behavioral patterns modified?

- 3.How pervasive and/or significant do these effects appear to be?

F. What evidence is there that students who have completed this course were adequately/inadequately prepared for subsequent courses for which this course is intended to prepare them?

_ G. To what extent do students rate their experience in the course as producing a meaningful and worthwhile contribution to their self-development?

1. In what ways were the students satisfied or dissatisfied with the course?

2. What suggestions do they have for improving the course?

- H. What evidence is there, if any, that the experience of teaching the course has a positive or negative effect upon faculty members?

\section{Institutional Costs \& Benefits}

- A. What are the time, space, equipment and facilities requirements of the course?

- B. What are the requirements of the course in terms of faculty and staff?

C. What other support services are required by the course?

D. What direct instructional costs are associated with this course?

_E. What benefits derive to the department, the college and the institution for having offered the course? 


\section{Questions to be Investigated in Evaluating Two Inter-Disciplinary Communications Skills Courses}

1. Course Objectives

A. What are the formal, stated objectives for each course? In what ways are the objectives similar? How are they different?

B. How appropriately do the stated objectives of each course match the needs of the target population?

C. What other unstated purposes, intents or goals do faculty members, administrators, and other interested persons have for each course?

2. Student Population Serviced

A. How comparable are the groups in terms of demographic variables such as age, sex, high school rank, SAT scores, academic major and full-time student status?

B. Why do students choose to enroll in one course instead of the other? Were students turned away from CMS $100 \mathrm{X}$ because of a ceiling on enrollment? How many?

3. Types of Learning Encounters \& Opportunities Provided

A. How do the two courses differ in terms of content and organization?

B. What are the primary modes of instruction used in each course? Approximately what proportion of the students' time (in class plus time spent on assignments) is devoted to listening to lectures, reading, writing, taking tests or small-group discussion?

C. What are the criteria for determining passing grades in each course?

4. Attendance and Course Completion Rates

A. To what extent do the courses differ in terms of average daily attendance?

B. What proportion of the students withdraw from or discontinue each course? To what extent was their discontinuance associated with factors related to the courses?

C. How do the courses compare in terms of the proportion of students who complete the course with passing grades (full credit)? 
5. Observable Student Outcomes
A. What gains in students' writing skills appear to have occurred in each course?
B. What gains in performance on a test of English grammar and usage appear to have occurred in each course?
C. What gains in students' oral presentation skills appear to have occurred in the trial course?
D. What effects did participation in the courses have upon stu- dents' writing apprehension and speech apprehension?
E. What effects did participation in the courses have upon stu- dents' attitudes towards the practical value and importance of clear and persuasive expression in both oral and written forms?

6. Student Satisfaction
A. To what extent were students' expectations of the courses met? In what ways were their expectations not met?
B. To what extent did students perceive the content and learning activities to be relevant to their needs and interests?
C. How did students rate the quality of the instruction provided?
D. What suggestions and recommendations did students have for improving the course?

7. Impact on Course Instructors

A. What activities do the instructors of the trial course perform as a team? What activities do they perform individually?

B. What effect does participation as an instructor in the trial course appear to have upon faculty members? How does it affect their philosophy of teaching? To what extent do they borrow ideas and methods from the trial course for use in other courses they teach?

C. What proportion of the instructors want to continue teaching the course? What proportion prefer to discontinue their involvement? Why?

8. Support Requirements
A. What are the space, time, physical facilities and equipment requirements of each course?
B. What instructional materials and support services are re-
quired by each course? What are the relative costs involved? 
C. What are the requirements of each course in terms of full-time equivalent faculty and staff? What dollar outlays per student are required?

D. What policy and/or logistical changes would be necessary to support the continued use of each course?

9. Feasibility of Expansion

A. What is the feasibility of creating additional sections of the course and offering it to a greater number of students each term? What problems would likely be encountered? 